\title{
THE DEVELOPMENT OF WELLNESS TOURISM THROUGH CREATIVITY
}

\author{
Mihaela STEFAN (HINT) ${ }^{a^{*}, \text { Andreea MARIN-PANTELESCU }}{ }^{b}$ \\ Diana-Eugenia PANAIT-IONCIC $\breve{A^{c}}$
}

\author{
${ }^{a} 1$ Decembrie 1918 University, Alba Iulia, Romania \\ ${ }^{b, c}$ Bucharest University of Economic Studies, Romania
}

\begin{abstract}
Quality of life and travel for the restoration of minds and souls are key concerns of the postpandemic era COVID-19. The devastating effect of the COVID-19 pandemic brought tourism at the beginning of 2021 to a $87 \%$ decrease in international tourist arrivals in January, as compared to 2020. Given the current trend, the World Tourism Organization estimated a decrease of $85 \%$ in the first quarter of 2021 over the same period of 2019. This represented a loss of 260 million international arrivals, compared to pre-pandemic levels according to International Tourism Highlights, 2020 Edition. This paper aims to analyze and investigate wellness tourism in Romania and the benefits it offers for mental health. It also proposes development solutions for tourism activities using the potential of people employed in this economic sector - their creativity and innovation. We want to offer innovative and creative solutions for the restoration of wellness tourism in Romania.
\end{abstract}

KEYWORDS: tourism, creativity, wellness tourism, COVID-19 pandemic, post-pandemic era

DOI: 10.24818/IMC/2021/01.10

\section{INTRODUCTION}

Tourist travel helps physical well-being and supports mental and emotional recovery. Of all the forms of tourism, wellness tourism is the one that provides the restoration of the body's health through various therapies and medical procedures, along with all the benefits that other forms of tourism include: fresh air, relaxation, hiking or heliomarine cures.

Wellness tourism is the association of tourism with the need to maintain and improve a person's well-being. Tourism promotes happiness and helps us relax our minds from stressful situations. This lowers the level of cortisone, the stress hormone, and brings us happiness and contentment. During the holidays, we reflect on our personal goals and interests, forgetting about conflict situations at work.

In recent decades, the need to include mental health among the top public health priorities has been increasingly recognized in Europe. For the European Commission, this has been a major goal for a long time. The Commission's Directorate-General for Health and Consumers has published a Green Paper on the development of a European strategy on mental health (European Commission, 2011). According to Tesone (2012), more than 80\% of Americans observed significant decreases in stress one day after the tourist trip. During the holidays, people are calm and relaxed, take resort tours, take photos and disconnect from everyday life.

Tourism helps you reinvent yourself. According to Health Tourism: The Benefits, "a tourist trip can teach you more about yourself than a hundred years of quietness." The so-called initiatory paths can

\footnotetext{
*Corresponding author. E-mail address: mihacont73@gmail.com
} 
enrich your soul. When we explore a country abroad, the new culture seduces us and we can reevaluate our lives and reinvent ourselves.

Travel increases happiness and satisfaction (Mental Health and Mental Health Services, n.d.). Apart from the obvious fact that you do not have to go to work, the trip offers you the opportunity to get away from your daily activities. New events and experiences help our brain to rest, thus increasing our mood and self-confidence. According to research by Hunter-Jones et al. (2020) life feels most fulfilled during tourist trips, when living new experiences and learning. Going and living where we feel excited and intimidated at the same time can help us strengthen ourselves mentally and emotionally.

Problems that seem unsolved, through creativity and tourism find their calmness and solution.

Wellness tourism is a market valued at $\$ 639$ billion (2019), and has experienced a strong growth between 2015-2019 of 10\% based on Euromonitor data (2021). International wellness tourists on average spent $\$ 1,528$ per trip, 53 percent more than the typical international tourist (McGroarty, 2021). The COVID-19 pandemic also hit wellness tourism with decreases between $85-95 \%$ for the arrivals of tourists for treatment in wellness destinations.

We believe that the stress and fear accumulated over the long and tumultuous period of the pandemic will provide a boom for wellness tourism.

This paper aims to analyze and investigate wellness tourism in Romania and the benefits it offers for mental health. It also proposes development solutions for wellness tourism activities using the potential of people employed in this economic sector - their creativity and innovation. We hope to offer innovative and creative solutions for the recovery of wellness tourism in Romania.

\section{LITERATURE REVIEW}

Decision makers in choosing a destination in health tourism have been in the concerns of many researchers such as: Lim (2016), Kara (2020), Rajah (n.d.) and Richards (2011).

Research has identified several significant factors for the attractiveness of the destination in health tourism, which determine the tourist's wellness option.

First of all, the proximity of the wellness resort or rather how easy it is for the tourist to reach the destination. This involves travel time, convenience, access to the airport, roads, railways, bureaucratic barriers (visas, formalities, etc.).

Then follows the cultural compatibility, which sets the level of mental comfort and refers to language, religion, customs and practices, gastronomy, the quality of local cuisine, but also the cooking possibilities for the tourists.

Third, the image of the destination, that is, what people know or think they know. This aspect is difficult to change. Wellness destinations need to accept what they are and rely on their strengths. The myth of the place, the real or imaginary perception also matters, the way in which these aspects are used makes the difference between a sought-after and a less sought-after wellness destination.

The state of the environment and the environment is another extremely important decision factor, which takes into account both the climate, natural and anthropic tourist attractions, and facilities of all kinds that we find in the tourist resort (Helmy, E., 2011).

Last but not least, the territory's infrastructure with basic services and existing facilities can substantially influence the choice of a tourist, regardless of the purpose of his trip. Also, some of the most important factors, in this case in health tourism, are the medical risks and benefits. Specifically, the guarantee of the success of a treatment.

Health tourism also tends to relate to a familiar area. There are tourists who have been to a certain holiday destination, so they can go to the same place for treatment. On the other hand, when it comes to health tourism, people will be increasingly inclined to the surrounding countries or even to their own country. 
There are two important axes that stimulate the discussion about health tourism in our country: the natural potential and the quality of human resources. The quality of human resources produced in Romania is demonstrated by the over 15,000 doctors working across borders, especially in developed countries in Europe, but also by the thriving medical tourism in Romania.

Natural therapeutic factors (thermal waters, mineral waters with a varied physico-chemical composition, carbonated waters and mofetary gases, lakes with mineral waters and muds) are present in over 200 localities in our country in a really generous variety. To this natural dowry are added the accumulations in some specialties in which Romania held important positions worldwide - for example in geriatrics and gerontology. Romania has the essential premises to respond to the need for health tourism products that include "well-being" (in the sense of good physical and mental condition) and the practice of a lifestyle that prevents degradation and disease.

Tourists as patients do not make decisions about competing destinations just by comparing the level of technology, quality and cost. It is a much more complex decision process. However, in an immature but sophisticated market, such as health tourism, most destinations put this at the forefront of their marketing strategies. The approach, which lies behind this facade and allocates time and resources on developing the concept of "destination attractiveness", is the one that will prove successful in the long run (Richards, 2013).

Romania has recognized potential for wellness tourism, and what adds responsible tourism can make the difference compared to other tourist destinations.

In a tourism enterprise, the process of creativity does not take place linearly; as a rule, it materializes in four successive stages, namely: the instinctive search, intuition, awareness and logical definition of new ideas.

In the phase of instinctive search, the process of searching for new ideas is still placed in the sphere of the subconscious, without having the outline of a definite purpose.

The second phase, intuition, is the connection point between conscious and subconscious, in this phase the interferences of various environmental forces are outlined and the connections that determine these interferences are noticed. Intuition, over time, will turn into an innovative idea, if it is applicable to the activity profile of the tourism enterprise.

Awareness is the third phase of the creative process, which aims to sort ideas, eliminate those that do not find applicability in the tourism enterprise and retain, in order to be analyzed, those ideas that prove useful for designing a new product for tourism, a new service or a more efficient process of providing services.

The logical definition of the new ideas aims, finally, at their transformation into operational processes, associated with the analysis of the economic aspects necessary for their implementation (possibilities and costs of implementation, estimation of advantages, etc.).

Innovation is "new ways of doing things or, better, unique combinations of factors of production" and places them at the heart of the work of an entrepreneur (Ottenbacher and Gnoth, 2005). According to Ottenbacher and Gnoth (2005), the person who introduces changes in economic life is represented by another class or, more correctly, by another group, because innovators do not necessarily recruit from a certain social class. Innovation should be seen and implemented as an opportunity that materializes itself in the form of a new or different product or service. Moreover, innovation can be an idea, a practice, a process or a product that transforms a proposed idea as a solution into an application that is perceived as new by an individual (Ottenbacher and Gnoth, 2005).

The specialized literature also proposes a possible taxonomic sketch of the innovations. It thus starts with real innovations - completely new services in a completely new market - and, in a downward direction, can lead to relatively minor changes to existing services. In the case of the latter it may be a matter of simply adapting an existing hospital service (such as in the case of hotels, replacing keys, as a means of access to rooms, with magnetic cards) or it may be a matter of increasing value through new ancillary facilities (turnkey apartments, as an alternative to classic hotel rooms, for short stays). 
Regarding internal resources, several studies have shown that innovation is first and foremost an entrepreneurial act that finds its origin in the will of management to distinguish itself from competition and to allocate time and resources for innovation, going as far as stimulating the creativity of employees that they associate with change.

Internal resources are often supplemented by external resources, given the limited capacity of enterprises. Small businesses are said to use external research centers or public bodies that support innovation more frequently than large companies (for example, the European Commission's information and innovation centers, innovation and technology research centers in France, etc.).

These bodies also bring a certain entrepreneurial culture of innovation and value to the regions where businesses operate. The behavior of several companies in a region can train other companies to innovate and encourage support bodies to be even more innovative.

Mental health is important at every stage of life - childhood, adolescence and adulthood - and is defined by a psychological level of well-being characterized by the functionality of the human being in satisfactory conditions of emotional, behavioral, biological and social adaptation. Mental health gives a person the ability to enjoy life, to identify a balance between activities, daily experiences and efforts to adapt psychologically in the context of their own value system.

An appropriate definition of health is not limited to the mere absence of disease. Mental health is affected by diseases and somatic defects of physical development, including the influence of the social environment.

According to the World Health Organization (WHO, 2021), mental health includes "subjective well-being, a sense of self-efficacy, autonomy, competence, intergenerational dependence, selfactualization of intellectual and emotional potential." WHO states that the well-being of human beings is included in the manifestation of their abilities, in their ability to cope with stress under normal living conditions, productive work and contribution to their community.

Mental health is a growing problem in many developed countries: 30\% of Australians report depressive symptoms, with implications for social sustainability. Therefore, a study of 238 tourists of all ages in Queensland, Australia who benefited from nature and adventure tourism in national parks tried to determine whether tourists visit the parks because they are happy or are happy because they visit the parks. A large majority of $82 \%$ chose the second option. Of those surveyed, $87.5 \%$ reported short-term emotional benefits, $60 \%$ medium-term recovery from stress-related problems, and 20\% reported long-term changes in worldview (Buckley, 2020).

\section{RESEARCH METHODOLOGY}

The research methodology consists primarily of investigation. We will mainly examine scientific articles published in prestigious journals, books, but also official documents issued by specialized institutions. Critical and comparative analysis of the main documents identified following the documentation process. Identification and collection of statistical data. Both the website of the National Institute of Statistics and Eurostat and Euromonitor, WHO, etc. will be used. Statistical data were processed and analyzed. Conducting research on the newest and most creative ways to involve tourism staff to increase the performance of wellness tourism.

\section{RESULTS AND DISCUSSIONS}

Wellness resorts focus mainly on treatment, namely medical care, convalescent care, especially for the sick or elderly, but some of the resorts also offer wellness packages.

Romania had in 2020 a number of 620 tourist accommodation units for wellness tourism, which represents $7 \%$ of the total accommodation units in Romania. Regarding the existing accommodation capacity for wellness tourism, in Romania, in 2020 we had 36,554 places, which represents $10 \%$ of the total accommodation in our country (National Institute of Statistics of Romania, 2021). 
Demand for wellness tourism has declined significantly due to the pandemic. Thus, in 2019 there were 1,133,359 tourist arrivals in the accommodation spaces in the wellness resorts in Romania, and in 2020 we had 601,326 tourist arrivals for wellness tourism. The decrease in the demand for wellness tourism in Romania in 2020 compared to 2019 was $47 \%$. Practically the total number of tourists for wellness tourism has halved in 2020 compared to 2019 due to the COVID-19 pandemic. The occupancy rate for tourist resorts in Romania was $22.8 \%$ in 2020, down $11 \%$ compared to 2019. Overnight stays for wellness tourism have been halved, from 4,805,188 tourist days in 2019 to $2,208,832$ tourist days in 2020 .

Table 1. The evolution of tourist indicators for wellness tourism in Romania

\begin{tabular}{|c|c|c|c|c|}
\hline & Tourism indicators & $\begin{array}{l}\text { Year } \\
2019\end{array}$ & $\begin{array}{l}\text { Year } \\
2020\end{array}$ & $\begin{array}{l}\text { Change } \\
2020 / 2019\end{array}$ \\
\hline 1 & $\begin{array}{l}\text { Number of tourist reception structures in wellness resorts } \\
\text { in Romania }\end{array}$ & 597 & 620 & $+3.85 \%$ \\
\hline 2 & $\begin{array}{l}\text { Number of accommodation places in wellness resorts in } \\
\text { Romania }\end{array}$ & 35643 & 36554 & $+2.55 \%$ \\
\hline 3 & Number of tourist arrivals in wellness resorts in Romania & 1133359 & 601326 & $-46.94 \%$ \\
\hline 4 & $\begin{array}{l}\text { Number of overnight stays of tourists in wellness resorts } \\
\text { in Romania }\end{array}$ & 4805188 & 2208832 & $-54.03 \%$ \\
\hline 5 & $\begin{array}{l}\text { Average length of stay (days) in wellness resorts in } \\
\text { Romania }\end{array}$ & 4.24 & 3.67 & $-13.44 \%$ \\
\hline
\end{tabular}

Source: created by the authors according to the statistical data processed from the platform of the

National Institute of Statistics of Romania http://statistici.insse.ro:8077/tempoonline/\#/pages/tables/insse-table

A slight increase in accommodation capacity for wellness tourism of $+2.55 \%$ and a slight increase in accommodation units for wellness tourism of $3.85 \%$ are noticed.

This shows investment initiatives in accommodation capacity in wellness resorts in Romania.

New constructions are welcome to improve medical procedures and to increase their efficiency and performance in curing many diseases. The cleanliness, hygiene, performance of the medical equipment together with the medical staff from the wellness resorts are essential for creating an attractive and innovative package of wellness services.

The demand for wellness services has been growing steadily from year to year with a sharp decline in the 2020 pandemic.

Foreign tourists are important because they represent the export of tourist services and through the currency brought to the country they contribute to its economic and social well-being. In the case of wellness tourism in 2019 in Romania we had 34,653 foreign tourist arrivals, and for 2020 there were 5,564 , which was an $84 \%$ reduction in foreign tourists who came for wellness tourism in Romania.

Table 2. The evolution of tourist arrivals for wellness tourism in Romania

\begin{tabular}{|l|l|r|r|r|}
\hline & Tourist arrivals for wellness tourism & \multicolumn{1}{c|}{$\begin{array}{c}\text { Year } \\
\mathbf{2 0 1 9}\end{array}$} & $\begin{array}{c}\text { Year } \\
\mathbf{2 0 2 0}\end{array}$ & \multicolumn{1}{c|}{$\begin{array}{c}\text { Change } \\
\mathbf{2 0 2 0 / 2 0 1 9}\end{array}$} \\
\hline 1 & Total arrivals & 1133359 & 601326 & $\mathbf{- 4 6 . 9 4 \%}$ \\
\hline 2 & Romanian tourist arrivals & 1098706 & 595762 & $\mathbf{- 4 5 . 7 8 \%}$ \\
\hline & Share from total (\%) & 96.94 & 99.07 & \\
\hline 3 & Foreign tourist arrivals & 34653 & 5564 & $\mathbf{- 8 3 . 9 4 \%}$ \\
\hline & Share from total $(\%)$ & 3.06 & 0.93 & \\
\hline
\end{tabular}

Source: created by authors according to the statistical data processed from the platform of the National Institute of Statistics of Romania http://statistici.insse.ro:8077/tempo-online/\#/pages/tables/insse-table 
Regarding the overnight stays of foreign tourists in the wellness resorts in Romania in 2019, 117,027 overnight stays were registered, while in 2020 the total number of overnight stays of foreign tourists for wellness tourism reached only 21,198 overnight stays. The decrease from one year to another, 2020 compared to 2019 regarding the overnight stays of foreign tourists in the wellness resorts in Romania was of minus $82 \%$.

Table 3. The evolution of tourist overnight stays for wellness tourism in Romania

\begin{tabular}{|l|l|r|r|r|}
\hline \multicolumn{1}{|c|}{ Wellness tourists overnights } & \multicolumn{1}{c|}{$\begin{array}{c}\text { Year } \\
\mathbf{2 0 1 9}\end{array}$} & \multicolumn{1}{c|}{$\begin{array}{c}\text { Year } \\
\mathbf{2 0 2 0}\end{array}$} & \multicolumn{1}{c|}{$\begin{array}{c}\text { Change } \\
\mathbf{2 0 2 0 / 2 0 1 9}\end{array}$} \\
\hline 1 & Total overnight stays & 4805188 & 2208832 & $\mathbf{- 5 4 . 0 3 \%}$ \\
\hline 2 & Overnight stays of Romanian tourists & 4688161 & 2187634 & $\mathbf{- 5 3 . 3 4 \%}$ \\
\hline & Share from total (\%) & 97.56 & 99.04 & \\
\hline 3 & Overnight stays of foreign tourists & 117027 & 21198 & $\mathbf{- 8 1 . 8 9 \%}$ \\
\hline & Share from total (\%) & 2.44 & 0.96 & \\
& & & \\
\hline
\end{tabular}

Source: created by authors according to the statistical data processed from the platform of the National Institute of Statistics of Romania http://statistici.insse.ro:8077/tempoonline/\#/pages/tables/insse-table

The economic analysis shows us how important it is to find creative and innovative solutions for the recovery of wellness tourism. The human resource in wellness tourism is essential because it performs all the procedures in the medical package.Below are some examples of good practices for the development of wellness tourism through creativity and innovation. What we want to argue is that humans are creative and innovative, not robots and machines. The human feelings that arise from human-human interaction are the most precious and valuable for revitalizing the activity of wellness tourism.

Example 1: A hotel chain Gran Tacande Wellness \& Relax in the tourist resort of Tenerife offers a jacuzzi on the terraces of all rooms and three large swimming pools surrounding the hotel, and another hotel chain Royal River \& Spa, Luxury Hotel offers a swimming pool in front of the terraces located on the ground floor with direct access to the sea, jacuzzi on each balcony of the rooms, showing creativity and competitiveness, respectively, and finally stimulating the growth of the number of tourists who want comfort and high quality services.

Example 2: An attractive niche in the field of tourism is the organization of hotels for treatment and for children. Many parents go on summer vacation with their children, and some just want to take a break and relax. There are proven ways to solve this problem - to offer it to a child dear to grandparents or to send him to a health camp. A small hotel designed especially for young guests is also considered a creative idea.

For this purpose, tourists can choose a beautiful room in an attractive area, comfortable rooms for 1 to 4 children, various types of entertainment programs for small agitations. The hotel for young guests should have competent educators, a small comfortable dining room and an attractive and educational games room for mental and physical health.

Example 3: it can be the creation of a unique green underground park representing a real value for tourists, people from all over the world who will come to see it. For such a park to function and grow normally, it is necessary to create special lighting and other conditions for the comfortable development of plants there. For this purpose, modern high-tech solutions will have to be used and thus the creation of such parks can become a source of excellent profits.

A unique concept in Europe, Club Aventura Praid from Harghita, the only adventure park open in a salt mine, is the result of an investment of about 250,000 euros. 
Creative thinking and imagination are important elements that lead to the improvement and continuous development of tourism activities.

Example 4: Modernization of wellness resorts with tradition and history in Romania: Băile Felix, Băile Herculane, Băile Balvanyos, Baile Tușnad, Baile Olănești, Baile Govora (Ministry of Tourism-Master-plan for the development of spa tourism, 2018). Stories in tourism represent creativity and pleasure for the ears of young and old alike. We all become aware when we listen to a legend. We practically walk on sacred places where the great heroes used to go or those who wanted energy from nature, water, sun, mountains.

Băile Felix is a village in Sânmartin commune, Bihor county, Crișana, Romania. Băile Felix is located $10 \mathrm{~km}$ south of Oradea. It is the largest permanent resort in Romania, ranking second, after the Black Sea coast, in terms of the number of accommodation in Romania. The existing facilities in this resort allow the successful treatment of rheumatism and neurological and gynecological diseases, and the medical bases have facilities for methods such as electrotherapy, hydrotherapy, aerosols, massages, paraffin wraps and other operations specific to spa treatments. The miraculous effects of the thermal water in Băile Felix have been known since the time of the Roman Empire. Tradition claims that in 1095 King Ladislaus, traveling through these lands, discovered thermal springs with beneficial effects on health.

Băile Herculane Resort is one of the oldest spas in the world, with a documentary evidence of over 1850 years. The uninterrupted existence of the resort was favored by hot springs, but also by its location in a valley sheltered by mountains.

Diversified treatment methods, from the classic spa cure to various methods of physiotherapy and electrotherapy, massages, acupuncture, offer this resort a high degree of attractiveness.

The resort has bicarbonate, chlorosodium, slightly sulfurized, warm thermal mineral waters. There are water springs with a temperature between 38 and 53 degrees Celsius, and some even between 46 and 56 degrees Celsius.

The springs in Băile Herculane are therapeutic resources of great value and are indicated mainly for: osteo-articular rheumatic diseases (spondylosis, discopathies, polyarthritis, sciatica); posttraumatic and neurological disorders (conditions after joint operations, conditions after fractures, paresis, paralysis); associated conditions (digestive, renal, cardiovascular, dermatological, endocrine, gynecological or nutritional).

Balvanyos Baths is a spa resort located in Covasna County. It is characterized by the presence of numerous springs of mineral water, by mofetic emanations of carbon dioxide - having a postvolcanic character, as well as by the beauty of the landscape.

Both water and mophetic gases have medium natural radioactivity. The air is ozonated and rich in negative aeroions. Mineral waters are carbonated waters known as "borvises used either in basins in external treatment or in internal treatment".

In total there are 57 springs in Balvanyos. All contain iron, and some also contain microelements such as bromine, iodine and fluorine. Traces of methane and propane are present in some springs, and others contain sulfuric acid. Some are slightly radioactive.

There are 3 skunks, the Puturoasa cave and the skunks arranged in the center of the resort and the one at Csiszár Baths. The mofetta gas from Pasul Turia from andesites with hornblende and biotite is below the radioactivity ratio, in the first place - in Romania.

Here you can treat conditions such as: high blood pressure; peripheral vascular diseases; Raynoud syndrome; scrocyanosis; livedo reticularis; mitral or aortic insufficiency; chronic venous insufficiency associated with atherosclerotic occlusive disease of the lower limbs; rheumatic diseases of the musculoskeletal system; digestive disorders, anemia; conjunctivitis.

Băile Tusnad are located in the southern part of the Ciuc depression, at an altitude of $650 \mathrm{~m}$, between the Harghita and Bodoc mountains, in a splendid gorge of the Olt. The position in the territory gives it a very picturesque setting, with strong ozonated air, rich in resinous aerosols and negative ions that make the resort have a tonic mountain bioclimate, favorable to mental comfort. 
There is written evidence about the mineral waters in the Tusnad area since the 18th century, in which the existence of mineral water springs with curative effects used by the locals of the nearby villages is mentioned.

Here are treated: cardiovascular diseases (states after myocardial infarction, circulatory disorders, valvular myocardial disorders, hypertension, circulatory disorders); nervous system disorders (asthenic neurosis, neurovegetative dystonias, secondary asthenic states, states of physical and intellectual fatigue); digestive disorders (stomach diseases, functional disorders of the colon, chronic gastritis, enterocolitis, biliary dyskinesia); endocrine disorders (mild hyperthyroidism, adrenal insufficiency, Basedow's disease).

Baile Govora is located in Valcea County, in the sub-Carpathian depression area in the northeast of Oltenia, $21 \mathrm{~km}$ from Ramnicul Valcea, on a derivation of the road to Horezu and Targu-Jiu, located in a region of hills covered by beech, oak, spruce, fir and acacia forests.

The spa resort Băile Govora is considered the second spa in terms of the number of iodized and brominated waters not only in Europe, but in the world, too.

The resort is recommended in the treatment of respiratory diseases (asthma, chronic bronchitis, pulmonary emphysema, microbial or viral pneumonia, rhinitis, sinusitis, pharyngitis, etc.), degenerative diseases (spondylosis, arthrosis, polyarthrosis) and rheumatic joint diseases (tendonitis, scapulohumeral periathritis ), as well as in the treatment of peripheral and central neurological dysfunctions (mild paresis, sequelae after polio, etc.) and of some post-traumatic dysfunctions and associated diseases (gynecological, endocrinological, cardiovascular, digestive, urinary). Modern balneological complexes are used with facilities for baths with iodized and sulfurous mineral waters, applications with hot mud, pneumotherapies, electrotherapy, quinotherapy, treatments with bee products. There is also a sanatorium for rheumatic and respiratory diseases for children.

Băile Olăneşti Resort is located $18 \mathrm{~km} \mathrm{NW}$ of Rm.Vâlcea, the county seat. It is crossed by the Olăneşti river valley, open to the south and closed to the north, which determines the penetration of the sun's rays all day long.

The resort is one of the few localities in the country that harmoniously combine two natural healing factors: the local climatic and topoclimatic factor, and the hydromineral factor consisting of mineral waters.

In Baile Olanesti resort there can be treated: diseases of the digestive system and ancillary glands (chronic enterocolitis, chronic gastritis, sequelae of the operated stomach, gastroduodenal ulcer), digestive disorders (chronic inflammatory bowel disease, chronic non-calculous colic, dyskinesia, stones) biliary, pancreatitis, diabetic hepatic steatosis), nutrition and metabolism diseases (diabetes, dyslipidemia, gout, hyperuricemia, obesity), chronic kidney disease (kidney stones, skin, cystitis, pyelocystitis), occupational diseases (chronic heavy metal poisoning : lead, mercury, arsenic), respiratory diseases (asthma, chronic asthmatic bronchitis, chronic allergic non-tuberculous rhinosinusitis), cardiovascular diseases, peripheral arteriopathy.

Example 5: Transmitting to young therapists the secrets of the profession of healers by experienced staff. A trained and experienced therapist knows that at an altitude of over $1000 \mathrm{~m}$, the air is clean, dry and free of pollen. On the other hand, the temperature is low, the oxygen content in the air is low, and the solar radiation is strong. The condition in areas with these characteristics is very useful for psoriasis and non-psoriasis allergic asthma, respiratory diseases and pulmonary hypotension and hypertension-dermatitis. Hilly and wooded areas also have a mild climate and mild irritation. The air quality is good, the wind and radiation are weighed, and the humidity and air temperature are balanced. It is recommended to carry out climate treatment in the mid-altitude mountain area to prevent the recovery of serious diseases such as heart disease, circulatory system, respiratory system and rheumatic diseases, comprehensive exhaustion and defense. When we talk about aerosol therapy, it is used to treat many ailments, especially those of a respiratory nature. This therapy involves the introduction of beneficial substances into the body in the form of liquid or solid 
particles, through the airways. Aerosol cure can be made in salt mines, but in this situation 4-hour sessions are recommended, repeated daily for at least 10 days. In Romania we can choose the salt mines from Slănic Prahova, Turda, Slănic Moldova and Praid.

Example 6: Involving tourists in performing procedures at home and continuing them as a healthy lifestyle through mindfulness therapies (finding balance, health and happiness naturally living the moment and being connected in nature). Creative tourism involves the active involvement of tourists in the development of wellness tourism through exercise, fresh air breathing, aromatherapy, the smell of plants, energizing drinking water, consuming more fresh and green juices, and daily meditation or simply the action of staying calm and focus on breathing, inhaling slowly and deeply and exhaling slowly, things that help a lot in reducing stress and improving oxygen intake. The experience offered by healers in wellness resorts can regulate energy flows in the body, and regenerate the mind.

Example 7: Forest bathing: The term is a metaphor that synthesizes the innovative practice of using the forest - as a pure natural space - to propose complementary therapies with wellness treatments in a framework of purity and balance, the one represented by nature. Tourists will be attracted by the authenticity of nature and the ecological wellness cottage, immersed in the forest, instead of the large infrastructures that value the latest technological equipment. Thus, destinations that can offer "peace of nature" have a major competitive advantage that they capitalize on through creativity. Romania's advantage offered by virgin forests and pure natural environment, increasingly known internationally, can be used to develop a new wellness offer, with national brand potential.

\section{CONCLUSIONS}

Wellness tourists are increasingly paying attention to travel and stay conditions and prefer tourist stays that can ensure their maintenance and improvement of their well-being compared to disruptive stays for their daily balance. It has thus become very important for a destination to promote its wellness offer, even if it is not the main reason for visiting tourists and therefore not the main selling point of the destination.

Clients of wellness tourism seek to give importance to measures to maintain their health in their daily activities and have generally begun to change their lifestyle in order to maintain their health. This trend of seeking physical and spiritual well-being is manifested by the emergence of a new industry: that of fitness and gyms, preventive and homeopathic treatments, organic food, alternative medicine.

Due to the natural factors of cure and the recognized know-how, the Romanian wellness resorts have all the advantages to respond to the clients' requests, provided that they are oriented and directed towards preventive, alternative approaches in addition to the traditional ones (which should also include the use of traditional herbal therapies, etc. in addition to classical spa therapy) to provide more innovative and diversified care services while maintaining very attractive and competitive costs compared to the European average.

Romanian spas can capitalize on real medical know-how and must develop creatively. Through the examples chosen, we consider that we have responded to the research topic and we have contributed to the innovative and creative solutions for the restoration of the wellness tourism in Romania.

\section{REFERENCES}

Buckley, R. (2020). Nature tourism and mental health: parks, happiness, and causation. Journal of Sustainable Tourism, 28(9), 1409-1424. doi:10.1080/09669582.2020.1742725

Euromonitor. (2021). Medical Tourism Industry Growing in Emerging Markets. https://blog.euromonitor.com/medical-tourism-industry-growing-in-emerging-markets/ 
European Commission (2011). Council conclusions on the European Pact for Mental Health and Well-being: results and future measures, Journal of the European Union, https://eurlex.europa.eu/LexUriServ/LexUriServ.do?uri=OJ:C:2011:202: 0001: 0003: RO: PDF

Health Tourism: The Benefits. (n.d.). Health Tourism. doi:10.4337/9781849805537.00009

Hunter-Jones, P., Flatt, S., Crolley, L., \& Neary, K. (2020). Mental health and social tourism: exploring the provider landscape. Handbook of Social Tourism, 98-107. doi:10.4337/9781788112437.00019

International Tourism Highlights. 2020 Edition (2020). https://www.e-unwto.org/doi/book/ $10.18111 / 9789284422456$

Kara, T. (2020). Health Tourism and Concept Complexity of Health Tourism in Turkey. International Journal of Health Management and Tourism. 5(3), 264 - 290, doi:10.31201/ijhmt.770680

Lim, W. M. (2016). Creativity and sustainability in hospitality and tourism. Tourism Management Perspectives, 18, 161-167. doi:10.1016/j.tmp.2016.02.001

Ministerul Turismului. (2018). Master-plan pentru dezvoltarea turismului balnear. http://turism.gov.ro/web/wp-content/uploads/2018/11/master-plan-pentru-dezvoltarea-turismuluibalnear.pdf

McGroarty, B. (2021). Wellness industry statistics \& facts. https://globalwellnessinstitute.org/pressroom/statistics-and-facts/

National Institute of Statistics. (2021). http://statistici.insse.ro:8077/tempo-online/\#/pages/tables/insse-table

Mental Health and Mental Health Services. (n.d.). PsycEXTRA Dataset. doi:10.1037/e333512004-001, https://pubmed.ncbi.nlm.nih.gov/34516178/

Ottenbacher, M. \& Gnoth, J. (2005). How to Develop Successful Hospitality Innovation. Cornell Hospitality Quarterly, 46(2), 205-222, Retrieved from: https://journals.sagepub.com/doi/10.1177/0010 880404271097

Rajah, K. K. (n.d.). Strategic creativity in tourism business. Strategic Management in Tourism, 3(1), 87-101. doi:10.1079/9781786390240.0087

Richards, G. (2011). Creativity and tourism. Annals of Tourism Research, 38(4), 1225-1253. doi:10.1016/j.annals.2011.07.008

Richards, G. (2013). Tourism development trajectories: From culture to creativity?. (2013). The Routledge Handbook of Cultural Tourism, 6(1), 320-326. doi:10.4324/9780203120958-51

Helmy, E. (2011). Typologies of health and wellness tourism. Health and Wellness Tourism, 4(2), 83-104. doi:10.1016/b978-0-7506-8343-2.00005-2

Tesone, D. (2012). Mental Maturity and Workplace Motivation for Hospitality and Tourism Practitioners. Journal of Tourism Research \& Hospitality, 01(03),118-223, doi:10.4172/2324-8807.1000105

World Health Organization (WHO). (2020). The top 10 causes of death. https://www.who.int/news$\mathrm{room} /$ fact-sheets/detail/the-top-10-causes-of-death 